\title{
BIOQ-BYWORD
}

\section{Role of Hormonal Manipulation in Prostate Cancer Management}

Syed Imran Ali Shah

Central Park Medical College

\begin{tabular}{|c|c|}
\hline & ABSTRACT \\
\hline ARTICLE INFO & Prostate cancer $(\mathrm{PCa})$ treatment has seen several important \\
\hline Article history: & $\begin{array}{l}\text { developments over the last few decades in the form of improved } \\
\text { surgical methods and advanced radiotherapy techniques but }\end{array}$ \\
\hline Published online: $31^{\text {st }}$ Jan, 2018 & $\begin{array}{l}\text { androgen deprivation therapy (ADT) still remains the cornerstone } \\
\text { of medical management of this common male malignancy. The }\end{array}$ \\
\hline Key words: & three-quarters of a century ago was a turning point that has since \\
\hline Prostate cancer & led to the development of various pharmacological agents which \\
\hline Androgen deprivation therapy & rely on the basic principle of hormonal manipulation in the form of \\
\hline 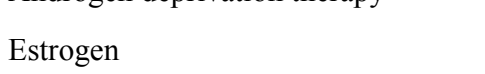 & ADT to alter disease progression. Initially employed for metastatic \\
\hline Luteinizing hormone releasing & disease only, ADT for $\mathrm{PCa}$ in the current clinical practice finds use \\
\hline Hormone & $\begin{array}{l}\text { multiple stages of the disease. The present review summarises the } \\
\text { chronological evolution of agents used for hormonal manipulation } \\
\text { in the management of } \mathrm{PCa} \text {, highlighting the pros and cons of each } \\
\text { and sheds light on the potential future advances in this area. }\end{array}$ \\
\hline
\end{tabular}

\section{Introduction}

Prostate cancer $(\mathrm{PCa})$ is one of the commonest male malignancies and is a leading cause of cancer-related morbidity and mortality worldwide ${ }^{[1]}$. In the United States alone, there were more than 180,000 new cases of $\mathrm{PCa}$ diagnosed in the year 2016 and more than 26,000 men died from $\mathrm{it}^{[2]}$. Charles Huggins in 1941 revealed the androgen-dependent nature of $\mathrm{PCa}$ by demonstrating that reduction in serum testosterone levels of patients with metastatic PCa brought about by castration with surgical orchiectomy or administration of diethylstilbestrol (DES), a synthetic oral form of estrogen, induced retardation of tumour growth and improvement of symptoms. Huggin's landmark discovery signalled the commencement of an era of development of therapies aimed at depleting androgens for the treatment of advanced disease. This hormonal manipulation by various modalities utilized as androgen deprivation therapy (ADT) has served as a crucial weapon in the battle against $\mathrm{PC}^{[3-5]}$.

\section{Androgen-dependence of prostate cancer}

It is now well known that $\mathrm{PCa}$ cells, normal or malignant, have an obligatory requirement of androgens for their growth and proliferation via activation of androgen receptors (AR) and withdrawal of androgens by ADT leads to $\mathrm{PCa}$ regression ${ }^{[6-7]}$. To-date, ADT remains the mainstay for treating 
advanced $\mathrm{PCa}$ and it has undergone substantial evolution over the last five decades ${ }^{[8]}$. Table 1 lists the different types of agents that have been used as ADT for PCa with their mechanisms of action.

\begin{tabular}{|l|l|}
\hline \multicolumn{1}{|c|}{ ADT Modality } & \multicolumn{1}{c|}{ Mechanism of Action } \\
\hline Surgical orchiectomy & $\begin{array}{l}\text { Removal of testes which are the chief producer of } \\
\text { testosterone, contributing 95\% to the circulating } \\
\text { testosterone pool }\end{array}$ \\
\hline Diethylstilbestrol (DES) & $\begin{array}{l}\text { Oral estrogen which diminishes testicular production of } \\
\text { androgens via negative feedback inhibition of the } \\
\text { hypothalamic-pituitary-gonadal axis }\end{array}$ \\
\hline $\begin{array}{l}\text { LHRH agonists } \\
\text { (leuprolide, goserlin, } \\
\text { triptorelin) }\end{array}$ & $\begin{array}{l}\text { Down-regulation of pituitary LHRH receptors, decrease } \\
\text { LH release which subsequently suppresses testosterone } \\
\text { production }\end{array}$ \\
\hline $\begin{array}{l}\text { LHRH antagonists } \\
\text { (degarelix) }\end{array}$ & $\begin{array}{l}\text { Inhibition of pituitary LHRH receptors directly } \\
\text { Non-steroidal } \\
\text { anti-androgens } \\
\text { (bicalutamide, flutamide, } \\
\text { nilutamide) }\end{array}$ \\
\hline $\begin{array}{l}\text { Steroidal anti-androgens } \\
\text { (cyproterone acetate) }\end{array}$ & $\begin{array}{l}\text { Blockade of enzyme CYP17 in adrenal steroid } \\
\text { biosynthetic pathway, reduction in adrenal androgen } \\
\text { production }\end{array}$ \\
\hline
\end{tabular}

Table 1. ADT modalities and their mechanisms of action

\section{Surgical orchiectomy}

Surgical orchiectomy (bilateral removal of testes) was one of the first methods used as $\mathrm{ADT}^{[3]}$, resulting in a rapid decline in serum testosterone to castrate levels ( $\leq$ $50 \mathrm{ng} / \mathrm{dL}$ or $1.7 \mathrm{nmol} / \mathrm{L}$ ) as the testes are the principal source of circulating androgens (producing nearly 95\% of total $)^{[9-10]}$. Despite being a cost-effective means, surgical orchiectomy is rarely performed these days particularly in the western world owing to the psychological trauma associated with it ${ }^{[11-12]}$.

\section{Diethylstilbestrol}

Diethylstilbestrol (DES), a synthetic oral oestrogen, was the first pharmacological agent used for treating metastatic PCa. Estrogenic hormones, by sharing the same steroid nucleus in their chemical structure as testosterone, suppress testicular production of Volume 2; Issue 1 
androgens via a negative feedback loop inhibiting the hypothalamic-pituitary-gonadal (HPG) axis ${ }^{[13]}$. Despite its efficacy, DES was withdrawn from routine clinical use following results from the 'Veterans Administration Cooperative Urological Research Group' (VACURG) studies which showed high dose DES $(5 \mathrm{mg})$ to cause cardiovascular toxicity in a third of treated patients with $15 \%$ experiencing a serious thromboembolic event ${ }^{[8][14]}$. However, subsequent trials showed cardiovascular mortality to be lower with low dose DES (1mg) as compared to high dose DES without any change in the beneficial oncological effects $^{[15]}$.

\section{Luteinising hormone releasing hormone agonists}

Luteinizing hormone releasing hormone agonists (LHRHa) are the most widely used pharmacological agents used as ADT for PCa. The molecular structure of the hypothalamic hormone luteinizing hormone releasing hormone (LHRH), also called gonadotropin releasing hormone $(\mathrm{GnRH})$, was characterised by Schally in 1971 that then developed synthetic decapeptides that acted as agonists of LHRH. Unlike the pulsatile hypothalamic release, short half-life and moderate receptor binding affinity of LHRH, chronic administration of synthetic LHRHa resulted in a continuous and prolonged action causing down-regulation of pituitary receptors. The net effect of pituitary receptor down-regulation is suppression of FSH and LH secretion from the anterior pituitary causing cessation of androgen production in the testicular Leydig cells and subsequent reduction of circulating testosterone ${ }^{[16]}$. Castrate levels of testosterone are achieved within a month of starting LHRHa therapy[9][17]. LHRHa were shown to have a similar survival outcome to surgical orchiectomy or DES $^{[17]}$. Due to their better psychological tolerability than surgical orchiectomy and improved cardiovascular safety profile than high dose DES, LHRHa gained worldwide acceptance in the 1980s and have since remained the treatment of choice for androgen sensitive advanced $\mathrm{PCa}^{[8]}$. LHRHa are typically offered for long term therapy following a diagnosis of advanced (incurable) disease either at presentation and following failure of radical therapy with curative intent ${ }^{[18]}$. LHRHa are now also given for short term as adjuvant or neo-adjuvant to RT for localized disease after they were shown to improve clinical and survival outcomes ${ }^{[19]}$. LHRHa not only suppress serum concentration of testosterone to $<5 \%$ of normal (castrate levels) but also result in an acute decline in estrogen levels to $<20 \%$ of normal (aromatisation of testosterone yields estrogen in males) [13][20]. As a consequence of diminished sex hormones, long term ADT with LHRHa has been associated with serious complications such as sarcopenia, anemia, sexual dysfunction and osteoporosis ${ }^{[21]}$. Intermittent ADT with LHRHa has been considered to overcome such toxicity. This involves cycling ADT with off-treatment periods, allowing testosterone to recover above castrate levels during the treatment cessation phase. Survival outcomes similar to continuous ADT have been shown with intermittent ADT in metastatic $\mathrm{PCa}^{[22]}$ and potential benefits relating to body composition changes have been suggested ${ }^{[23]}$. However current evidence appears inadequate in establishing intermittent ADT for routine clinical use ${ }^{[24-25]}$.

Initial exposure to LHRHa leads to a 'testosterone flare reaction', due to preliminary transient activation of HPG-axis which leads to a surge in the production of testosterone. In a few patients, this can cause complications such as exacerbation of bone pain from skeletal metastasis and worsening of urinary obstructive symptoms. The flare phenomenon is blocked by administering anti-androgens a week before starting LHRHa and continuing for 2-3 weeks afterward $^{[26]}$.

\section{Anti-androgens}

Anti-androgens, also called androgen antagonists, are oral agents that inhibit AR signalling by competitively 
blocking the AR ligand-binding sites. There are two distinct classes of anti-androgens; steroidal (cyproterone acetate) and non-steroidal (bicalutamide, flutamide and nilutamide). In addition to AR blockade, steroidal anti-androgens also exhibit progestogen-like activity that results in central HPG inhibition and decrease in serum testosterone ${ }^{[27]}$.

Anti-androgens are commonly employed for preventing the flare reaction from LHRHa therapy ${ }^{[26]}$ and they have also been used in combination with LHRHa (combined androgen blockade; CAB). CAB was the first method of ADT shown to improve survival in patients with advanced disease as compared to surgical orchidectomy or DES ${ }^{[28]}$.

Suppression of testosterone synthesis in the testes does not completely eliminate serum androgens as adrenal production accounts for $5 \%$ of the circulating androgen pool ${ }^{[10]}$. Further, the potent androgen DHT is also synthesized locally in the prostate from sex hormone precursor DHEA produced in the adrenal glands. The residual androgens from a non-testicular origin stimulate $\mathrm{PCa}$ growth and $\mathrm{CAB}$ has been used to enhance the efficacy of ADT by countering this effect $^{[10][29]}$.

\section{Luteinising hormone releasing hormone antagonists}

LHRH antagonists are ADT agents that bind to pituitary receptors and block the release of $\mathrm{LH}$ and FSH, without causing the flare reaction seen with LHRHa. Degarelix, available as a monthly depot injection, is the first approved LHRH antagonist for treatment of advanced PCa. Degraelix induces a rapid decline in serum testosterone levels $(96 \%$ patients achieve castrate levels within 3 days) and maintains castrate levels effectively ${ }^{[30]}$. Findings from analysis of pooled data of prospective randomised controlled trials (RCT) comparing degarelix to LHRHa suggest improved survival and musculoskeletal toxicity outcomes with degarelix ${ }^{[31]}$.

\section{Parenteral estrogen}

Oral estrogen DES was previously used as ADT but its use was curtailed owing to concerns over cardiovascular and thromboembolic toxicity ${ }^{[14]}$. It is now evident that oral administration exposes the liver to very high concentrations of estrogen via portal circulation. This first pass through the liver upregulates hepatic synthesis of pro-coagulant proteins and induces a hypercoagulable state, thereby escalating the risk of serious thromboembolic and cardiovascular events such as myocardial infarction and stroke ${ }^{[32]}$.

Parenteral oestrogen administration (intramuscular, transdermal) not only results in central suppression of androgen production but also mitigates the thromboembolic consequences of oral therapy by avoiding first-pass effect through the liver. Castrate levels of testosterone for $\mathrm{PCa}$ growth arrest can be achieved by this strategy, with little effect on hemostatic profile ${ }^{[33-35]}$. By replacing endogenous estrogen lost otherwise as a result of contemporary ADT with LHRHa, parenteral estrogen may potentially mitigate the estrogen deficiency related serious adverse events such as osteoporosis ${ }^{[36-37]}$. Previous data from studies using parenteral estrogen as ADT for PCa have highlighted the bone-sparing potential of this treatment. A study of patients with advanced PCa $(n=20)$ treated with transdermal oestradiol as primary ADT reported increases in total hip and lumbar spine BMD after a year of starting therapy (38). In another study of men with advanced PCa $(n=910)$ with 9 years follow-up, none of the patients on intramuscular oestrogen (polyestradiol phosphate) developed any serious skeletal event compared to 18 on CAB (35).

The PATCH (Prostate Adenocarcinoma TransCutaneous Hormones) study is an ongoing randomised clinical trial, now in Phase III, comparing transdermal estradiol with LHRHa in locally advanced and metastatic PC. In the first stage $(n=254)$ of the phase II study, similar rates of significant CVS events (the primary outcome) were reported in both trial arms. Volume 2; Issue 1 
Serum glucose and cholesterol profiles were also shown to be more favourable in the estradiol group than in the LHRHa group ${ }^{[39]}$. Results from a sub-study of the phase II trial evaluating bone health showed decreased lumbar spine BMD with LHRHa compared to baseline while it increased with estrogen patches ${ }^{[40]}$. Parenteral estrogen appears to be an effective and safe therapeutic option for the treatment of PC. Future data from trials such as PATCH will contribute to the evidence-base required to establish parenteral estrogen as an alternative to contemporary ADT with LHRHa.

\section{Treatment of castration-resistant prostate cancer}

Following initial response to ADT, PCa invariably progresses to a state of resistance called castration-resistant prostate cancer (CRPC) which is associated with a poor prognosis and reduced survival. Continued AR signalling due to intratumoral androgen synthesis, AR mutations and AR overexpression has been suggested to propel disease progression despite castrate levels of testosterone achieved with conventional $\mathrm{ADT}^{[8][41]}$. A number of novel treatments offering survival benefit for CRPC have recently been introduced ${ }^{[42][43]}$. These include cytotoxic chemotherapy (docetaxel, cabazitaxel) ${ }^{[44]}$, new ADT agents (abiraterone, enzalutamide) ${ }^{[45-47]}$ and immunotherapy (sipuleucel-T) ${ }^{[48]}$. Low-dose oral DES (1-3 mg) has also been demonstrated to be effective and safe as a CRPC treatment with a 5-10\% rate of thromboembolic events ${ }^{[49-50]}$. Table 2 lists the treatment options for CRPC and their mechanisms of action. The management of CRPC has been transformed with the introduction of these new agents but questions regarding their optimum timing, combination therapy and toxicity profile still need to be answered.

\begin{tabular}{|c|c|c|}
\hline Treatment & Type & Mechanism of Action \\
\hline $\begin{array}{l}\text { Docetaxel, } \\
\text { Cabazitaxel }\end{array}$ & $\begin{array}{l}\text { Cytotoxic } \\
\text { chemotherapy }\end{array}$ & $\begin{array}{l}\text { Arrest tumour growth by binding to tubulin protein and } \\
\text { causing cell cycle arrest }\end{array}$ \\
\hline Abiraterone & $\begin{array}{l}\text { Androgen } \\
\text { deprivation } \\
\text { therapy }\end{array}$ & $\begin{array}{l}\text { Suppresses intratumoral androgen synthesis by } \\
\text { inhibiting both 17- } \alpha \text {-hydroxylase and 17,20 lyase } \\
\text { activities of microsomal enzyme cytochrome P450 } \\
\text { isoform-17 }\end{array}$ \\
\hline Enzalutamide & Anti-androgen & $\begin{array}{l}\text { Multi-step inhibition of androgen signalling cascade } \\
\text { (competitive binding to AR, reduced nuclear } \\
\text { translocation, impaired DNA binding) }\end{array}$ \\
\hline Sipuleucel-T & Immunotherapy & $\begin{array}{l}\text { Activated autologous cytotoxic T-cell vaccine targets } \\
\text { prostatic acid phosphatase expressed by tumour cells }\end{array}$ \\
\hline DES & $\begin{array}{l}\text { Synthetic oral } \\
\text { oestrogen }\end{array}$ & $\begin{array}{l}\text { Inhibits gonadal, extragonadal and intratumoral } \\
\text { androgen synthesis }\end{array}$ \\
\hline
\end{tabular}


Table 2. Novel treatment options for castration-resistant prostate cancer

\section{Conclusion}

Hormonal manipulation has seen considerable evolution over the years and still retains its place at the heart of PCa management. As we continue to better understand the biochemical mechanisms of $\mathrm{PCa}$ progression, the role of hormonal manipulation is becoming even more pronounced. Newer, more efficacious ADT agents are being developed currently which promise a great deal for the future. However, a major consideration among all this excitement is the ever-growing evidence about the toxicities associated with $\mathrm{ADT}$ and there is a dire need to introduce strategies aimed at mitigating them.

\section{References}

[1] Wong MC, Goggins WB, Wang HH, Fung FD, Leung C, Wong SY, et al. Global Incidence and Mortality for Prostate Cancer: Analysis of Temporal Patterns and Trends in 36 Countries. European urology. 2016;70(5):862-74.

[2] Siegel RL, Miller KD, Jemal A. Cancer statistics, 2016. CA: a cancer journal for clinicians. 2016;66(1):7-30.

[3] Huggins CB, Hodges CV. Studies on prostatic cancer. I. The effect of castration, of estrogen and of androgen injection on serum phosphatases in metastatic carcinoma of the prostate. Cancer research. 1941;1:293-7.

[4] Huggins CB. The hormone-dependent cancers. JAMA. 1963;186:481-3.

[5] Nobelprize.org. The Nobel Prize in Physiology or Medicine 1966: Nobel Media AB; 2015 [cited 2015 June]. Available from: http://www.nobelprize.org/nobel_prizes/medicine/laure ates/1966/.
[6] Gomella LG. Effective testosterone suppression for prostate cancer: is there a best castration therapy. Rev Urol. 2009;11(2):52-60.

[7] Sharifi N, Gulley JL, Dahut WL. Androgen deprivation therapy for prostate cancer. JAMA. 2005;294:238-44.

[8] Wong YN, Ferraldeschi R, Attard G, de Bono J. Evolution of androgen receptor targeted therapy for advanced prostate cancer. Nature reviews Clinical oncology. 2014;11(6):365-76.

[9] Oefelein MG, Feng A, Scolieri MJ, Ricchiutti D, Resnick MJ. Reassessment of the definition of castrate levels of testosterone: Implications for clinical decision making. Urology. 2000;56:1021-4.

[10] Miller WL. Androgen biosynthesis from cholesterol to DHEA. Mol Cell Endocrinol. 2002;198:7-14.

[11] Lee D, Nielsen SK, van Keep M, Andersson F, Greene D. Quality of Life Improvement in Patients Treated with Degarelix versus Leuprorelin for Advanced Prostate Cancer. The Journal of urology. 2015;193(3):839-46.

[12] Paula AAPD, Piccelli HRS, Pinto NP, Teles AG, franqueiro AG, Maltez ARL, et al. Economical impact of orchiectomy for advanced prostate cancer. Int Braz J Urol. 2003;29:127-32.

[13] Auchus ML, Auchus RJ. Human steroid biosynthesis for the oncologist. J Investigative Med. 2012;60:495-503.

[14] Byar DP. The veterans administration cooperative urological research group's studies of cancer of the prostate. Cancer. 1973;32:1126-30.

[15] Scherr DS, Pitts WR, Jr. The nonsteroidal effects of diethylstilbestrol: the rationale for androgen 
deprivation therapy without estrogen deprivation in the treatment of prostate cancer. J Urology. 2003;170(5):1703-8.

[16] Schally AV. Treatment of hormone-dependent cancer with analogues of hypothalamic hormones. Experimental and clinical studies. Annals of the New York Academy of Sciences. 1987;496:602-7.

[17] The-Leuprolide-study-group. Leuprolide versus diethylstilbestrol for metastatic prostate cancer. NEJM. 1984;311(20):1281-6.

[18] Connolly RM, Carducci MA, Antonarakis ES. Use of androgen deprivation therapy in prostate cancer: indications and prevalence. Asian $\mathrm{J}$ Andrology. 2012;14(2):177-86.

[19] Denham JW, Steigler A, Lamb DS, Joseph D, Mameghan H, Turner S, et al. Short-term androgen deprivation and radiotherapy for locally advanced prostate cancer: results from the Trans-Tasman Radiation Oncology Group 96.01 randomised controlled trial. Lancet Oncol. 2005;6:841-50.

[20] Garnick MB. Leuprolide versus diethylstilbestrol for previously untreated stage D2 prostate cancer. Results of a prospectively randomized trial. Urology. 1986;27:21-8

[21] Allan C, Collins VR, Frydenberg M, McLachlan RI, Matthiesson KL. Androgen deprivation therapy complications. Endocr-Relat Cancer. 2014.

[22] Mottet N, Van Damme J, Loulidi S, Russel C, Leitenberger A, Wolff JM. Intermittent hormonal therapy in the treatment of metastatic prostate cancer: a randomized trial. BJU international. 2012. Epub 2012/04/17.

[23] Spry NA, Taaffe DR, England PJ, Judge JS, Stephens DA, Peddle-McIntyre C, et al. Long-term effects of intermittent androgen suppression therapy on lean and fat mass: a 33-month prospective study.
Prostate cancer and prostatic diseases. 2013;16(1):67-72.

[24] Dason S, Allard CB, Wang JG, MD(c), Hoogenes $\mathrm{J}$, Shayegan B. Intermittent androgen deprivation therapy for prostate cancer: translating randomized controlled trials into clinical practice. Canadian J Urology. 2014;21:28-36.

[25] Hussain M, Tangen CM, Berry DL, Higano CS, Crawford ED, Liu G, et al. Intermittent versus continuous androgen deprivation in prostate cancer. $\mathrm{N}$ Engl J Med. 2013;368(14):1314-25.

[26] Thomas BC, Neal DE. Androgen deprivation treatment in prostate cancer. BMJ. 2013;346:e8555-e.

[27] Gillatt D. Antiandrogen treatments in locally advanced prostate cancer: are they all the same? Journal of cancer research and clinical oncology. 2006;132 Suppl 1:S17-26.

[28] Labrie F, Dupont A, Belanger A, Lefebvre FA, Cusan L, Raynaud JP, et al. New hormonal therapy in prostate cancer: combined use of a pure antiandrogen and an LHRH agonist. Hormone research. 1983;18(1-3):18-27.

[29] Labrie F. Combined blockade of testicular and locally made androgens in prostate cancer: A highly significant medical progress based upon intracrinology. J Steroid Biochem Mol Biol. 2014.

[30] Klotz L, Boccon-Gibod L, Shore ND, Andreou C, Persson BE, Cantor P, et al. The efficacy and safety of degarelix: a 12-month, comparative, randomized, open-label, parallel-group phase III study in patients with prostate cancer. BJU international. 2008;102(11):1531-8.

[31] Klotz L, Miller K, Crawford ED, Shore N, Tombal B, Karup C, et al. Disease Control Outcomes from Analysis of Pooled Individual Patient Data from Five Comparative Randomised Clinical Trials of 
Degarelix Versus Luteinising Hormone-releasing Hormone Agonists. European urology. 2014.

[32] Von Schoultz B, Carlstrom K, Collste L, Eriksson A, Henriksson P, Pousette A, et al. Estrogen therapy and liver function--metabolic effects of oral and parenteral administration. Prostate. 1989;14:389-95.

[33] Langley RE, Godsland IF, Kynaston H, Clarke NW, Rosen SD, Morgan RC, et al. Early hormonal data from a multicentre phase II trial using transdermal oestrogen patches as first-line hormonal therapy in patients with locally advanced or metastatic prostate cancer. BJU international. 2008;102(4):442-5.

[34] Ockrim JL, Lalani E-N, Kakkar AK, Abel PD. Transdermal Estradiol Therapy for Prostate Cancer Reduces Thrombophilic Activation and Protects against Thromboembolism. The Journal of urology. 2005;174(2):527-33.

[35] Hedlund PO, Damber JE, Hagerman I, Haukaas S, Henriksson P, Iversen P, et al. Parenteral estrogen versus combined androgen deprivation in the treatment of metastatic prostatic cancer: part 2. Final evaluation of the Scandinavian Prostatic Cancer Group (SPCG) Study No. 5. Scandinavian journal of urology and nephrology. 2008;42(3):220-9.

[36] Ockrim J, Lalani el N, Abel P. Therapy Insight: parenteral estrogen treatment for prostate cancer--a new dawn for an old therapy. Nature clinical practice Oncology. 2006;3(10):552-63.

[37] Ockrim JL, Lalani EN, Laniado ME, Carter SS, Abel PD. Transdermal estradiol therapy for advanced prostate cancer--forward to the past? J Urology. 2003;169(5):1735-7. Epub 2003/04/11.

[38] Ockrim JL, Lalani EN, Banks LM, W.E. S, Blomley MJ, Patel S, et al. Transdermal estradiol improves bone density when used as single agent therapy for prostate cancer. J Urology. 2004;172:2203-7.
[39] Langley RE, Cafferty FH, Alhasso AA, Rosen SD, Sundaram SK, Freeman SC, et al. Cardiovascular outcomes in patients with locally advanced and metastatic prostate cancer treated with luteinising-hormone-releasing-hormone agonists or transdermal oestrogen: the randomised, phase 2 MRC PATCH trial (PR09). Lancet Oncol. 2013;14(4):306-16.

[40] Langley RE, Duong T, Jovic G, Cafferty FH, Honeyfield L, Abel RL, et al. Bone density in men receiving androgen deprivation therapy for prostate cancer: a randomized comparison between transdermal estrogen and luteinising hormone-releasing hormone agonists. J Clinical Oncology. 2014;32(5s):suppl; abstr 5067.

[41] Cereda V, Formica V, Massimiani G, Tosetto L, Roselli M. Targeting metastatic castration-resistant prostate cancer: Mechanisms of progression and novel early therapeutic approaches. Expert Opin Investig Drugs. 2014;23:469-87.

[42] Agarwal N, Di Lorenzo G, Sonpavde G, Bellmunt J. New agents for prostate cancer. Annals of oncology : official journal of the European Society for Medical Oncology / ESMO. 2014;25(9):1700-9.

[43] Castro E, Romero N, Olmos D. State-of-the-art treatment in castration-resistant prostate cancer. EMJ Oncology. 2014;2:100-5.

[44] Sundararajan S, Vogelzang NJ. Chemotherapy in the treatment of prostate cancer - the past, the present, and the future. Am J Hematol Oncol. 2014;10:14-21.

[45] Mostaghel EA. Abiraterone in the treatment of metastatic castration-resistant prostate cancer. Cancer Manag Res. 2014;6:39-51. doi: 10.2147/CMAR.S39318.

[46] Schalken J, Fitzpatrick JM. Enzalutamide: Targeting the androgen signalling pathway in metastatic castration-resistant prostate cancer. BJU international. 2015. doi: 10.1111/bju.13123. 
[47] Rehman Y, Rosenberg JE. Abiraterone acetate: oral androgen biosynthesis inhibitor for treatment of castration-resistant prostate cancer. Drug design, development and therapy. 2012;6:13-8.

[48] Kantoff PW, Higano CS, Shore ND, Berger ER, Small EJ, Penson DF, et al. Sipuleucel-T immunotherapy for castration-resistant prostate cancer. N Engl J Med. 2010;363:411-22.
[49] Wilkins A, Shahidi M, Parker C, Gunapala R, Thomas K, Huddart R, et al. Diethylstilbestrol in castration-resistant prostate cancer. BJU international. 2012;110(11 Pt B):E727-35.

[50] Bosset PO, Albiges L, Seisen T, de la Motte Rouge T, Phe V, Bitker MO, et al. Current role of diethylstilbestrol in the management of advanced prostate cancer. BJU international. 2012;110:E826-9. 